\title{
Clinical utility gene card for: Meckel syndrome - update 2016
}

\author{
Carsten Bergmann ${ }^{\star, 1,2}$, Valeska Frank ${ }^{1}$ and Riitta Salonen ${ }^{3}$ \\ European Journal of Human Genetics (2016) 24, doi:10.1038/ejhg.2016.33; published online 20 April 2016
}

Update to: European Journal of Human Genetics (2011) 19, doi:10.1038/ejhg.2010.255; published online 2 February 2011

\section{DISEASE CHARACTERISTICS}

1.1 Name of the disease (synonyms)

MKS, Meckel syndrome, Meckel-Gruber syndrome, Dysencephalia splanchnocystica. ${ }^{1-14}$

\subsection{OMIM\# of the disease}

type 1 MIM\# 249000, type 2 MIM\# 603194, type 3 MIM\# 607361, type 4 MIM\# 611134, type 5 MIM\# 611561, type 6 MIM\# 612284, type 7 MIM\# 267010, type 8 MIM\# 613885, type 9 MIM\# 614209, type 10 MIM\# 614175, type 11 MIM\# 615397, type 12 MIM\# 616258.

1.3 Name of the analyzed genes or DNA/chromosome segments MKS1, TMEM216 (MKS2), TMEM67 (MKS3), CEP290 (MKS4), RPGRIP1L (MKS5), CC2D2A (MKS6), NPHP3 (MKS7), TCTN2 (MKS8), B9D1 (MKS9), B9D2 (MKS10), TMEM231 (MKS11), KIF14 (MKS12), TMEM107 (MKS13) and TMEM138, TMEM237.

\subsection{OMIM\# of the gene(s)}

MKS1, MIM\# 609883; TMEM216, MIM \#613277, TMEM67, MIM\# 609884; CEP290, MIM\# 610142; RPGRIP1L, MIM\# 610937; CC2D2A, MIM\# 612013; NPHP3, MIM\# 608002; TCTN2, MIM\# 613885; B9D1, MIM\# 614209; B9D2, MIM\# 614175; TMEM231, MIM\# 614949, KIF14, MIM\# 611279; TMEM107, MIM\# 616183; TMEM138, MIM\# 614465; TMEM237, MIM\# 614423.

\subsection{Mutational spectrum}

Data according to published literature and HGMD database (https:// portal.biobase-international.com).

Exact figures are still hard to provide on the contribution of each of the above genes to the total mutational load in Meckel-Gruber syndrome. Although there is evidence for further genetic heterogeneity, major MKS genes are MKS1, MKS3/TMEM67 and MKS6/ CC2D2A, followed by MKS4/CEP290. Although all kind of pathogenic variants (missense and nonsense mutations, splice site mutations, deletions and insertions) are present, the majority is truncating, whereas in MKS3 also missense mutations are frequent.

Although some genotype-phenotype correlations may allow for prioritization of genes in single cases, efficient testing has only been possible since establishment of next-generation sequencing (NGS) and the possibility of simultaneous investigation of all genes to be discussed in a fetus.

\subsection{Analytical methods}

In consanguineous and multiplex pedigrees, initial linkage analysis (targeted and genome-wide) with subsequent sequencing in case of compatible haplotypes is possible, but often replaced by sequencing now.

In sporadic cases originating from non-consanguineous marriages, direct sequencing (by Sanger's method or NGS) is usually performed due to private variants in most cases.

\subsection{Analytical validation}

(Potential) pathogenic variants are bidirectionally sequenced, preferentially on a second DNA sample of the index patient. Segregation analysis in the parents of the index patient to ensure compound heterozygosity and/or to exclude a large deletion on the other allele for a homozygous variant should be performed. In case of a novel variant, family studies of affected and non-affected persons can be helpful, as well as testing of ethnically matched controls to exclude a pathogenic variant. Gene transcripts should be analyzed in case of potential splicing variants.

1.8 Estimated frequency of the disease (Incidence at birth ('birth prevalence') or population prevalence) $1 / 20000$.

1.9 If applicable, prevalence in the ethnic group of the investigated person

In Finland and other isolated and/or consanguineous cohorts, MKS is much more frequent.

(most probably $>1 / 5000-10000$ ).

\subsection{Diagnostic setting}

\begin{tabular}{lll}
\hline & Yes & No \\
A. (Differential) diagnostics & $\square$ & $\square$ \\
B. Predictive testing & $\square$ & $\square$ \\
C. Risk assessment in relatives & $\bigotimes$ & $\square$ \\
D. Prenatal & $\square$ & $\square$
\end{tabular}

${ }^{1}$ Center for Human Genetics, Bioscientia, Ingelheim, Germany; ${ }^{2}$ Department of Medicine, University Freiburg Medical Center, Freiburg, Germany; ${ }^{3}$ Norio-Centre, Rinnekoti Foundation, Helsinki, Finland

*Correspondence: Professor C Bergmann, Center for Human Genetics, Bioscientia, Konrad-Adenauer-Strasse 17, Ingelheim 55218 , Germany. Tel: +49 6132781476 ; Fax: +49 6132781 298; E-mail: carsten.bergmann@bioscientia.de or carsten.bergmann@uniklinik-freiburg.de Received 22 May 2015; revised 4 March 2016; accepted 16 March 2016; published online 20 April 2016 


\section{TEST CHARACTERISTICS}

\begin{tabular}{|c|c|c|c|c|}
\hline & \multicolumn{2}{|c|}{ Genotype or disease } & \multirow{2}{*}{$\begin{array}{l}\text { A: True positives } \\
\text { B: False positives }\end{array}$} & \multirow{2}{*}{$\begin{array}{l}\text { C: False negatives } \\
\text { D: True negatives }\end{array}$} \\
\hline & Present & Absent & & \\
\hline \multicolumn{5}{|l|}{ Test } \\
\hline Positive & $A$ & $B$ & $\begin{array}{l}\text { Sensitivity: } \\
\text { Specificity: }\end{array}$ & $\begin{array}{l}A /(A+C) \\
D /(D+B)\end{array}$ \\
\hline Negative & C & D & $\begin{array}{l}\text { Positive predictive value: } \\
\text { Negative predictive value: }\end{array}$ & $\begin{array}{l}A /(A+B) \\
D /(C+D)\end{array}$ \\
\hline
\end{tabular}

2.1 Analytical sensitivity

(proportion of positive tests if the genotype is present) nearly $100 \%$.

\subsection{Analytical specificity}

(proportion of negative tests if the genotype is not present) nearly $100 \%$.

\subsection{Clinical sensitivity}

(proportion of positive tests if the disease is present)

Clinical sensitivity is not known so far. Currently, more than a dozen genes with a number of variants have been identified as the cause for Meckel syndrome. There is variation of the distribution of these variants in different populations, and additional genes can be expected to be identified in future years.

\subsection{Clinical specificity}

(proportion of negative tests if the disease is not present)

A hallmark of ciliopathies is their significant clinical and genetic heterogeneity with considerable overlap between different entities. In particular, Meckel syndrome is allelic to a group of other ciliarelated disorders:

- Joubert syndrome (CC2D2A, CEP290, RPGRIP1L, TCTN2, TMEM67, TMEM138, TMEM216, TMEM231, TMEM237)

- Bardet-Biedl syndrome (CEP290, MKS1)

- Nephronophthisis (CEP290, NPHP3, RPGRIP1L, TMEM67)

Recently, single fetuses with features of MKS were described with variants in EVC2 and EXOC4. The first fetus was found to carry a novel homozygous variant (in-frame insertion of eight amino acids) in EVC2, a gene usually described to cause the ciliopathy Ellis-van Crefeld syndrome (EVC). Typical features for EVC such as skeletal and cardiac findings were lacking in this individual. The other fetus was described to harbor a novel homozygous missense variant in EXOC4 that encodes an exocyst protein recruited to the basal body. Both of these fetuses were detected by exome sequencing and had consanguineous parents and were of Arab origin.

\subsection{Positive clinical predictive value}

(life-time risk to develop the disease if the test is positive). $100 \%$.

2.6 Negative clinical predictive value

(Probability not to develop the disease if the test is negative). In any case (index case tested or not), there is no risk to develop the disease for an unaffected individual (always present before birth).

\section{CLINICAL UTILITY}

3.1 (Differential) diagnostics: The tested person is clinically affected (To be answered if in 1.10 'A' was marked)

Yes.

3.1.1 Can a diagnosis be made other than through a genetic test?

\begin{tabular}{ll}
\hline No & $\square$ (continue with 3.1.4) \\
Yes $\square$ & \\
Clinically & $\square$ \\
Imaging & $\square$ \\
Endoscopy & $\square$ \\
Biochemistry & $\square$ \\
Electrophysiology & Autopsy and histological verification of the typical \\
Other (please describe) & findings is reasonable.
\end{tabular}

3.1.2 Describe the burden of alternative diagnostic methods to the patient

The condition is usually lethal.

3.1.3 How is the cost effectiveness of alternative diagnostic methods to be judged?

Clinical work-up and imaging might be less cost-intensive, however, the obtained data is less clear with lower specificity and sensitivity.

3.1.4 Will disease management be influenced by the result of a genetic test?

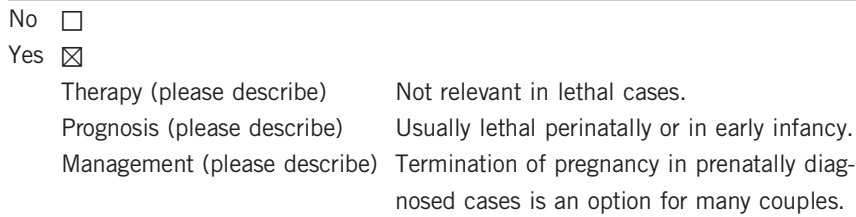

3.2 Predictive setting: The tested person is clinically unaffected but carries an increased risk based on family history

(To be answered if in 1.10 ' $\mathrm{B}$ ' was marked)

3.2.1 Will the result of a genetic test influence lifestyle and prevention?

Early prenatal diagnostics and/or preimplantation genetic diagnosis (PGD) become possible.

3.2.2 Which options in view of lifestyle and prevention does a person at risk have if no genetic test has been done (please describe)?

Not applicable.

3.3 Genetic risk assessment in family members of a diseased person (To be answered if in 1.10 ' $\mathrm{C}$ ' was marked)

Carrier testing of family members becomes possible.

Please note: due to the rarity of the disease, this is primarily important for couples that are related or of Finnish origin (eg, MKS1 founder mutation).

3.3.1 Does the result of a genetic test resolve the genetic situation in that family?

Yes. 
3.3.2 Can a genetic test in the index patient save genetic or other tests in family members?

Yes.

3.3.3 Does a positive genetic test result in the index patient enable a predictive test in a family member?

No.

\subsection{Prenatal diagnosis}

(To be answered if in 1.10 ' $\mathrm{D}$ ' was marked)

Early genetic testing typically after chorionic villi sampling. Ultrasound scan usually detect clinical features characteristic of MKS such as cystic kidneys and malformations of the brain and extremities.

3.4.1 Does a positive genetic test result in the index patient enable a prenatal diagnostic?

Yes.

\section{IF APPLICABLE, FURTHER CONSEQUENCES OF TESTING}

Please assume that the result of a genetic test has no immediate medical consequences. Is there any evidence that a genetic test is nevertheless useful for the patient or his/her relatives? (Please describe)

Early prenatal diagnostics and/or PGD become possible as well as carrier testing of family members.

Please note: due to the rarity of the disease, this is primarily important for couples that are related or of Finnish origin (eg, MKS1 founder mutation).

\section{CONFLICT OF INTEREST}

The authors declare no conflict of interest.

\section{ACKNOWLEDGEMENTS}

This work was supported by EuroGentest, an EU-FP6 supported NoE, contract number 512148 (EuroGentest Unit 3: 'Clinical genetics, community genetics and public health', Workpackage 3.2). CB and VF are employees of Bioscientia/ Sonic Healthcare. Work in the Bergmann lab is supported by the German Research Fund (DFG), Collaborative Research Centre (SFB) KIDGEM 1140.

1 Salonen R: The Meckel syndrome: clinicopathological findings in 67 patients. Am J Med Genet 1984; 18: 671-689.

2 Paavola P, Salonen R, Baumer A et al: Clinical and genetic heterogeneity in Mecke syndrome. Hum Genet 1997; 101: 88-92.

3 Consugar MB, Kubly VJ, Lager DJ et al: Molecular diagnostics of Meckel-Gruber syndrome highlights phenotypic differences between MKS1 and MKS3. Hum Genet 2007; 121: 591-599.

4 Dawe HR, Smith UM, Cullinane AR et al: The Meckel-Gruber Syndrome proteins MKS1 and meckelin interact and are required for primary cilium formation. Hum Mol Genet 2007; 16: 173-186

5 Frank V, Bruchle N, Mager S et al: Aberrant splicing is a common mutational mechanism in MKS1, a key player in Meckel-Gruber syndrome. Hum Mutat 2007; 28 638-639.

6 Khaddour R, Smith U, Baala L et al: Spectrum of MKS1 and MKS3 mutations in Meckel syndrome: a genotype-phenotype correlation. Hum Mutat 2007; 28: 523-524.

7 Tallila J, Salonen R, Kohlschmidt N, Peltonen L, Kestilä M: Mutation spectrum of Meckel syndrome genes: one group of syndromes or several distinct groups? Hum Mutat 2009; 30: E813-E830.

8 lannicelli M, Brancati F, Mougou-Zerelli S et al: Novel TMEM67 mutations and genotype-phenotype correlates in meckelin-related ciliopathies. Hum Mutat 2010; 31 E1319-E1331.

9 Frank V, Bergmann C: Meckel Syndrome and Related Disorders. Chichester, UK: John Wiley \& Sons Ltd, 2013.

10 Shaheen R, Faqeih E, Alshammari MJ et al: Genomic analysis of Meckel-Gruber syndrome in Arabs reveals marked genetic heterogeneity and novel candidate genes. Eur J Hum Genet 2013; 21: 762-768.

11 Arts HH, Knoers NV: Current insights into renal ciliopathies: what can genetics teach us? Pediatr Nephrol 2013; 28: 863-874.

12 Barker AR, Thomas R, Dawe HR: Meckel-Gruber syndrome and the role of primary cilia in kidney, skeleton, and central nervous system development. Organogenesis 2014; 10: 96-107.

13 Filges I, Nosova E, Bruder E et al: Exome sequencing identifies mutations in KIF14 as a novel cause of an autosomal recessive lethal fetal ciliopathy phenotype. Clin Genet 2014; 86: 220-228.

14 Shaheen R, Almoisheer A, Faqeih E et al: Identification of a novel MKS locus defined by TMEM107 mutation. Hum Mol Genet 2015; 24: 5211-5218. 